WellBeing International

WBI Studies Repository

$3-2013$

\title{
A Study of Sharing and Reciprocity in Grey Parrots (Psittacus erithacus)
}

\author{
Franck Péron \\ Paris West University Nanterre La Défense \\ Maria John \\ University of Leipzig \\ Stephanie Sapowicz \\ Brandeis University \\ Dalila Bovet \\ Paris West University Nanterre La Défense \\ Irene M. Pepperberg \\ Brandeis University
}

Follow this and additional works at: https://www.wellbeingintlstudiesrepository.org/acwp_asie

Part of the Animal Studies Commons, Behavior and Ethology Commons, and the Comparative Psychology Commons

\section{Recommended Citation}

Péron, F., John, M., Sapowicz, S., Bovet, D., \& Pepperberg, I. M. (2013). A study of sharing and reciprocity in grey parrots (Psittacus erithacus). Animal cognition, 16(2), 197-210.

This material is brought to you for free and open access by WellBeing International. It has been accepted for inclusion by an authorized administrator of the WBI Studies Repository. For more information, please contact wbisr-info@wellbeingintl.org.

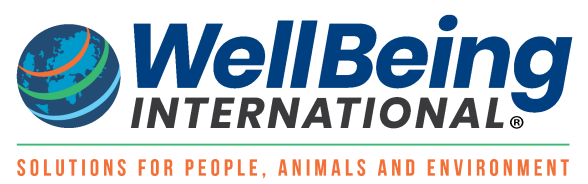




\title{
A Study of Sharing and Reciprocity in Grey Parrots (Psittacus erithacus)
}

Franck Péron ${ }^{1}$, Maria John ${ }^{2,3}$, Stephanie Sapowicz ${ }^{3}$, Dalila Bovet ${ }^{1}$, Irene M. Pepperberg ${ }^{3,4}$

${ }^{1}$ Paris West University Nanterre La Défense

${ }^{2}$ University of Leipzig

${ }^{3}$ Brandeis University

${ }^{4}$ Harvard University

\section{KEYWORDS}

Psittacus erithacus, parrot, value attribution, nonhuman sharing, reciprocity, mutualism

\begin{abstract}
Demonstrations of nonhuman ability to share resources and reciprocate such sharing seem contingent upon the experimental paradigm used (note Horner et al. in PNAS 108:13847-13851, 2011). Here, such behaviour in Grey parrots (Psittacus erithacus) was tested in two experiments, both designed to avoid possible issues involving apparatus complexity, visible reward options, and physical competition and/or limited communication between subjects. In both studies, two birds, working in dyads, took turns in choosing one of four different coloured cups with differing outcomes: empty (null, nonrewarding), selfish (keeping reward for oneself), share (sharing a divisible reward), or giving (donating reward to other). In Experiment 1, each bird alternated choices with a conspecific; in Experiment 2, each bird alternated with the three humans with different specific intentions (selfish, giving, or copying bird's behaviour). In both experiments, birds could learn to cooperatively reward a partner at little cost to themselves-by sharingand potentially maximize overall reward by reciprocating such sharing. Experiment 1 results differed depending upon which bird began a session: Only our dominant bird, as follower, was willing to share. In Experiment 2, birds' responses tended towards consistency with human behaviour. Our dominant bird was willing to share a reward with a human who was willing to give up her reward, was selfish with the selfish human, and tended towards sharing with the copycat human; our subordinate bird tended slightly towards increased sharing with the generous human and selfishness with the selfish human, but did not change behaviour with the copycat.
\end{abstract}

\section{Introduction}

Much scientific study currently centres on sharing, reciprocity, and prosociality-determining whether subjects behave so as to benefit another individual, usually at little personal cost, and if such behaviour is contingent upon similar behaviour in a partner (e.g. Dawkins 2010; Rustagi et al. 2010). Children are often tested to see how and when such behaviour develops and what behavioural elements and social conditions must be in place for it to be exhibited (e.g. Warneken et al. 2011; see Kärtner et al. 2010). By studying group-living nonhuman primates, however, researchers also aim to uncover what evolutionary 
pressures may have selected for such behaviour: whether the selection process depends on culture, genes, a combination thereof-or simply requires social living (see Bell et al. 2009; Hamilton 1975; Simpson and Beckes 2009). From an evolutionary standpoint, researchers (see Jolly 1966; Humphrey 1976) have long argued that primate intelligence was a correlate of complicated social and ecological systems and long lives; that is, an outcome of selection processes favouring animals that flexibly transfer skills across domains and remember and act upon knowledge of detailed intragroup social relations. The expectation was that long-lived primates in coherent social groups-humans and closely related apeswould likely demonstrate prosociality, sharing or reciprocity: They might demonstrate an understanding of the underlying concepts by maximizing possible payoff during a task by remembering and repaying positive actions of those within their social group or at least attend to one other's behaviour-even if selfish or neutral-in order to reciprocate in kind.

Such behaviour in nonprimates has, in contrast, received relatively little attention and then mostly in corvids (e.g. DiLascio et al. 2012; Scheid et al. 2008; Schwab et al. 2012; Seed et al. 2008; von Bayern et al. 2007). Notably, data on avian species might provide evidence for convergent evolution of such traits, whereas lack thereof might assist in determining what ethological, ecological, and possibly even neurological constraints might be preconditions for their existence. Given many parallels between primates and some corvids and psittacids-complex social lives, highly developed cognitive and communicative abilities (e.g. referential vocal behaviour, cooperation and reconciliation, possible deception and coalition formation) that suggest convergent evolution (Bugnyar 2007; Clayton and Emery 2005; Emery 2004; Emery et al. 2007; Fraser and Bugnyar 2010a, b, 2011; Pepperberg 1999, 2010; Seed et al. 2008), parrots might also be good subjects for studies involving some level of prosocial behaviour. Specifically, long-term studies on Grey parrots show they learn best in social contexts (Pepperberg 1999; Pepperberg et al. 1998, 1999, 2000), that their cognitive competence is often comparable to that of young children (Pepperberg 1999, 2006a, b; Pepperberg and Gordon 2005; Pepperberg and Carey 2012), and that although Grey parrots do not, like some other psittacids, engage in cooperative breeding and nest sharing, in the wild they are highly social, live in large flocks (May 2004), display altruistic behaviours (e.g. regurgitation, mutual interaction such as grooming), and cooperate by mobbing in the presence of a predator (Jones and Tye 2006). Recent studies suggest some ability to cooperate with one another (Péron et al. 2011a) and to adapt responses according to experimenters' behavioural cues (Giret et al. 2009; Péron et al. 2010, 2011b).

Interestingly, a reviewof current literature suggests that the presence or absence of prosocial behaviour, sharing, or reciprocity appears dependent not only upon the species tested but also upon parameters of the task used: whether the task involves solicitation of food (and whether food is visible) or solicitation of assistance, the need to coordinate behavior either in concert or sequentially, whether subjects must perform the same tasks or somewhat different tasks hierarchically, and whether dominance rank is taken into account (see Horner et al. 2011 for a review; note also Henderson and Woodward 2011). We begin by discussing some of these issues according to species; the purpose of this discussion is to provide justification for the techniques we chose to employ.

Studies on great apes (primarily chimpanzees), the evolutionarily closest primates to humans, corroborate effects of experimental design on results. Directly observable food rewards seemed to inhibit prosociality (Bullinger et al. 2011; Jensen et al. 2006; Silk et al. 2005; Vonk et al. 2008). The few studies examining reciprocity (e.g. Brosnan et al. 2009; de Waal 1997; Melis et al. 2008, 2009; Yamamoto and Tanaka 2009; Yamamoto et al. 2009) found weak effects of partners' previous behaviour, primarily with groomingfood exchanges. If assistance rather than food sharing was studied, chimpanzees showed some cooperation (Warneken et al. 2007). Results also appeared contingent upon whether tasks involved simultaneous reward versus cooperation to enable a partner to receive reward subsequently (Greenberg 
et al. 2010; note Melis et al. 2009; Yamamoto et al. 2009). Dominance hierarchies may play a role (Melis et al. 2009), and whether partners actively solicit assistance (Yamamoto et al. 2009, but see Melis et al. 2011). Using token exchange rather than reciprocal actions, orangutans but not chimpanzees, bonobos, or gorillas cooperated with conspecifics (Brosnan and Beran 2009; Bullinger et al. 2011; Dufour et al. 2009; Pelé et al. 2009). When tokens were chosen, not exchanged, chimpanzees did demonstrate some prosociality (Horner et al. 2011).

Monkey studies also vary in aims, design, and results. Neither capuchins nor Tonkean macaques engaged in conspecific token exchanges (Pelé et al. 2010) but capuchins showed limited cooperative, reciprocal altruism for direct food reward and prosociality when (a) it was pitted against selfishness, (b) partners were familiar and visible, and (c) subjects chose tokens that were immediately traded for reward (Brosnan et al. 2006; de Waal et al. 2008; Hattori et al. 2005; Lakshminarayanan and Santos 2008; Takimoto et al. 2010). Dominance influenced results for long-tailed macaques (Massen et al. 2010, 2011): higher ranked individuals shared more; lowest ranked ones were more selfish. Such behaviour might have occurred because here subordinates could be selfish without immediate (e.g. aggressive) reprisal and dominants could share at no personal cost, but the results also suggest that dominants may use prosociality to emphasize their rank (see de Waal 1989; Zahavi 2004).

Cooperatively breeding monkeys (e.g. Callithrichids) have also been studied-species in which stronger and more human-like social interactions (Hrdy 2009) might promote prosociality (Burkart et al. 2007) despite further evolutionary distance from humans. Again, results depended upon experimental conditions and aims: Common marmosets (Callithrix jacchus) but not cottontop tamarins (Saguinus oedipus) chose to cooperate compared to a control in which food was delivered to an empty cage (Burkart et al. 2007; Cronin et al. 2009; Stevens 2010). Cottontops, however, were prosocial when the task used immediate equal rewards (Cronin and Snowdon 2008); and, in a later study, prosociality was not initially strong but emerged over time (Cronin et al. 2010).

Given our awareness of these many issues that could affect the experimental outcome-e.g. apparatus complexity, visible reward options, physical competition and/or limited communication between subjectswe designed a protocol to avoid as many of them as possible. And, as a first step, we chose to examine behaviour related to, but not isomorphic with, prosociality: Would our birds share rewards if the payoff for sharing and being selfish were the same, and, given the turn-taking nature of the task we designed, would they reciprocate-or learn to reciprocate-to maximize payoff over time?

Because responding can be affected strongly by the sight or absence of food rewards (e.g. Warneken et al. 2007; also Boysen et al. 1996), we used a token system: Birds could choose one of four presented cups, leading to (a) no reward (null/spiteful, sensu Hamilton 1964), (b) reward for oneself (selfish), (c) reward for the other individual (giving), or (d) equal reward for both (sharing). (We use "giving" to emphasize the action without imputing intent.) Our parrots had a long history of understanding relationships between use of human vocal labels and various outcomes (Pepperberg 1999; Pepperberg and Wilkes 2004) and in manipulating small objects such as the cups for reward (e.g. Pepperberg et al. 1997); thus we did not expect any difficulty in their learning the value of each individual cup colour.

Despite involving multiple conditions/outcomes, this protocol had advantages of simplicity of use-birds did not need to learn to manipulate a novel apparatus, coordinate physical actions, or overtly communicate with each other, although results of each others' actions were immediately made visible by the human experimenter. Notably, the system also avoided simultaneous competition for overt rewards, as only one bird could choose at a time, and prevented the birds, who were, outside of sessions, housed in or on separate cages within a large room, from engaging in physical retribution. (NB: They interact aggressively if in close proximity in the absence of humans.) We studied the four conditions 
simultaneously in order to better model real-life conditions, rather than constraining birds to a limited number of artificial, human-designated choices that might not reflect behaviour in the wild.

Dyadic responding may be affected by the relationship between the subjects involved (e.g. de Waal et al. 2008; Massen et al. 2010, 2011; Melis et al. 2009); we thus performed two experiments to address this issue. The first involved a parrot-parrot dyad in which one bird was known to be dominant. Here we alternated birds' positions as leader and follower to see whether their behaviour would be affected if the dominant bird had to follow and the subordinate bird was given the chance to lead. The second experiment associated each parrot with humans who, with respect to each bird, would consistently be selfish, giving, or copy the parrot's action ("copycat"), and with whom dominance issues should not exist. To ensure that birds did not learn to respond to a particular human by watching each other's sessions, the human who was selfish with one parrot was giving with the other; humans never altered choices when interacting with a given bird. The copycat, whose stance was essentially neutral, maintained her role with both birds. These parrots had been trained by humans for over a decade (e.g. Pepperberg 1999; Pepperberg and Shive 2001; Pepperberg and Wilcox 2000; Pepperberg and Wilkes 2004), and other Grey parrots in similar situations have, as noted above, learned to adapt their responses to overt human behavioural actions (Giret et al. 2009; Péron et al. 2010, 2011a, b), thus we expected them to associate a stance with a particular human and react appropriately, much as do primates (Intentional/Accidental: Call and Tomasello 1998; Unable/Unwilling: Call et al. 2004; Phillips et al. 2009).

Parrots were thus tested as to their choice among four differentially valued tokens, and whether they would react to the behaviour of their various partners. We predicted that, if parrots understood the reward system, they would, in the first study, develop a preference for the sharing token and thereby maximize their overall pay-off. Specifically, the immediate reward would be the same if they shared or were selfish but, if both attended to each other's choices and consistently chose to share (at no cost to themselves, a limited form of prosociality), they could maximize their total reward. In the second study, in contrast, we predicted they would either replicate the choice of the experimenter, as their standard training involves learning from human modelling sessions (Pepperberg 1999), or attempt to act as demonstrators themselves by choosing the sharing cup to maximize reward.

Individual personalities of our two birds clearly might affect our results; however, our limited subject pool confers certain advantages. Because several studies show reciprocity is not contingent on short-term, titfor-tat rules but rather long-term interactions (review in Massen et al. 2011), detailed knowledge of our two birds' interactions with each other for over 9 years and with humans for over a decade, and their stable dominance relationship, provides some bases for our findings. Unfortunately, few captive flocks of Grey parrots are available for study, and those may be comprised of 'rescue' birds, sometimes with serious social problems (e.g. prior abuse, previously living without social interaction of any sort, etc.) that could hinder studies of prosociality and reciprocity, both with other birds and humans. Our results can be seen as a first step in examining sharing and reciprocity in Grey parrots and should provide impetus for further examination of this behaviour, a topic of considerable interest given the similarities of the psittacine lifestyle to that of primates in nature.

\section{General methods}

\section{Subjects and housing}

Two hand-reared male Grey parrots were tested during July-December 2009: 14-yr-old Griffin and 11-yrold Arthur. Griffin was dominant to Arthur. Both birds have been the subject of continuing studies on comparative cognition and interspecies communication (e.g. Pepperberg 1999, 2004; Pepperberg et al. 1998, 1999, 2000; Pepperberg and Shive 2001; Pepperberg and Wilcox 2000; Pepperberg and Wilkes 
2004). Details of housing conditions are in Pepperberg and Wilkes (2004). Outside of testing, birds lived separately in or on large cages out of reach of one another, in the same room, but sometimes display aggressively. Birds were never food or water deprived at any time during experiments.

Fig. 1 Experiment 1. Position of birds and tray during trials; during trials, cups are arranged so as to be equidistant from the beak of the bird that makes the choice. In a Griffin chooses as Arthur watches; in b human gives Griffin the reward (selfish choice); in c Arthur gets ready to choose as Griffin watches
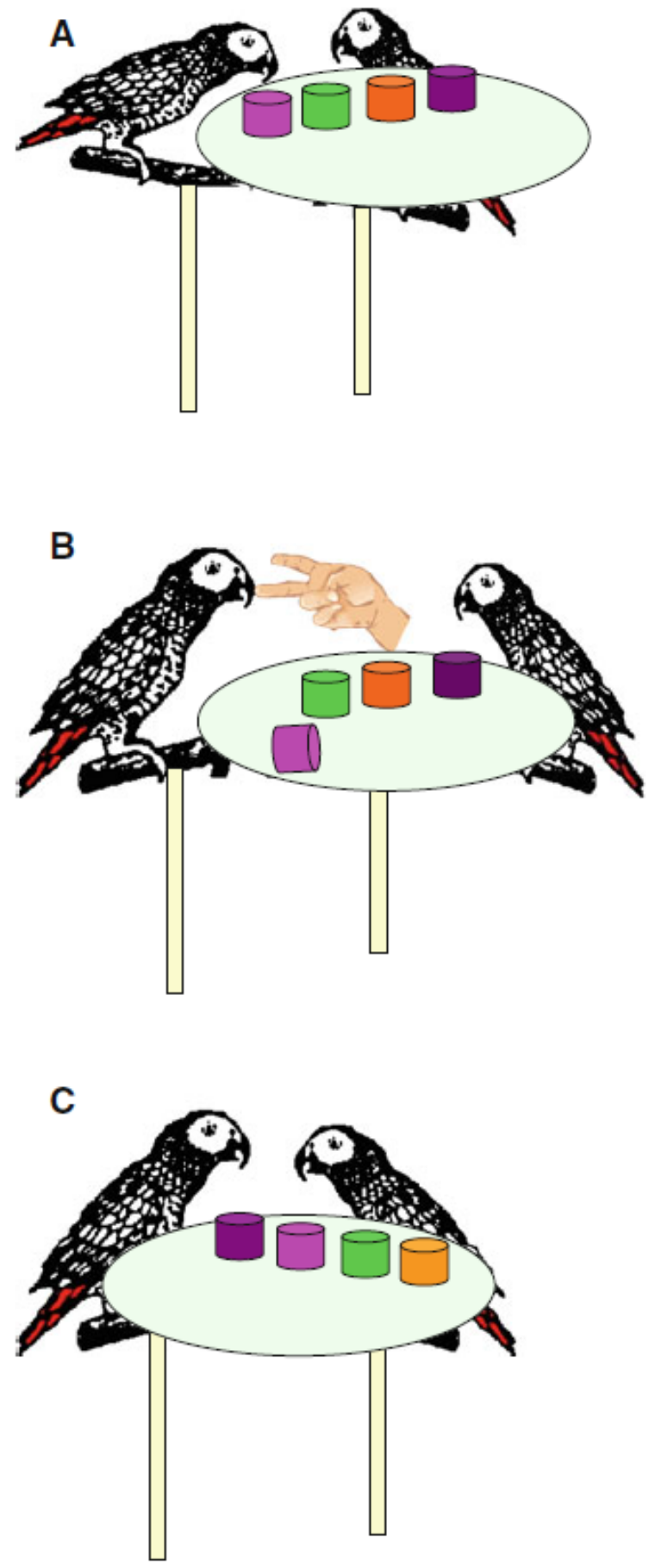


\section{Materials and general method}

Four same-sized plastic cups of differing colours (First Years Stack N Count Cups ${ }^{\mathrm{TM}}$ ) were placed on a felt-covered tray equidistant from a parrot's beak (Fig. 1), and rewards consistent with each cup colour were put under each cup without birds observing the placement (see below). The setup ensured that human cuing via gaze of a particular choice of cup would not be an issue: Cups were closely spaced $(<5$ $\mathrm{cm}$ ) on a tray and the human head was about $30 \mathrm{~cm}$ away from the tray, a situation in which parrots have not previously been shown to react to human gaze direction (Pepperberg 1990, 1999), unlike that of Giret et al. (2009) in which Grey parrots did respond to human gaze when objects were $1.6 \mathrm{~m}$ apart and the human face was deliberately turned in the direction of one of the objects.

The same materials were used for all experimental trials. The specific cups were novel, but both birds had interacted with similar cups previously (e.g. object permanence, Pepperberg et al. 1997) and thus showed no neophobia or other aversive behaviour towards these items. Because Griffin and another Grey parrot, Alex, had already shown in object permanence tasks that they would, in the absence of another bird, appropriately choose the cup among several that contained hidden rewards (Pepperberg et al. 1997), we did not test to see whether competition was required for birds to track rewards. We first tested to ensure that birds had no colour biases, then attributed arbitrary values to each cup colour. The tray was also familiar, having been used with both birds for several years to present various study items (e.g. Pepperberg et al. 1997; Pepperberg and Wilkes 2004). Rewards-pieces of cashews, almonds, occasionally small candies-were special treats not available except in experimental sessions.

No familiarization phase was needed; birds were used to interacting with the cups in this manner. If a bird hesitated, he was told "Go pick up cup." For each trial, we recorded the choice of the birds and, in Experiment 1, any additional behaviour of each individual (vocal production, displacement, etc.). In Experiment 2, additional physical but not vocal behaviour was noted.

\section{Experiment 1}

\section{Protocol}

Birds perched close enough to one another to observe each other's choice, but outside of beak range to avoid possible aggression. Out of view of the birds, an experimenter placed the cups on a tray, with the appropriate rewards hidden underneath: The green cup held 2 treats, pink and orange cups held 1 each, the violet cup held none. If a bird chose (a) green cup-sharing, he and his partner each got treats; (b) pink cup—selfish, only he got a treat, (c) orange cup-giving, only his partner got a treat, and (d) violet cup_null (spiteful/opt out), no one got treats. Cups were equidistant from the beak of the bird making the choice, and order was counterbalanced such that one bird started one particular session of trials (the leader) and, in most instances, order was reversed in the next session (i.e. that bird became the follower). Birds worked as a dyad, such that each two-choice trial consisted of the following pattern: The tray was presented to the lead bird; after he chose a cup (either by picking it up or pecking it), the experimenter intervened and distributed the reward according to the cup's value. While birds ate the reward, the tray was rebaited (out of sight of the birds), then immediately presented to the follower for his choice and subsequent reward disbursement by the experimenter. Inter-choice and intertrial intervals (i.e. time needed to re-bait and re-present the tray, approximately 12-15 s) were kept as consistent as possible; the idea was to model what might be a feeding session in the wild, where the first bird to arrive at, for example, a fruiting tree, might have some advantage, but then feeding by the flock is more or less simultaneous, excepting various affiliative and aggressive flock interactions (May 2004). 
We also examined the relevance of cup placement on the tray, by changing their order randomly, to determine whether birds would indeed respond to colour/value versus spatial array; that is, we needed to test whether birds might have spatial preferences that could affect their choices separate from the reward level of the cup. In Experiment 1, we used random changes so birds could not deduce or anticipate systematic changes in presentations. We could then compare their behaviour with other sessions in which cup order had not been altered.

Fig. 2 Experiments 1 and 2. Payoff matrix, showing the number of treats involved in each possible outcome for a two-choice trial, depending on a bird's choice and its partner's choice. For example: If both individuals chose to share on a given trial, each bird would get two rewards (upper left corner); if individual 1 acts selfishly but individual 2 shares, individual 1 gets two rewards and individual 2 gets only one (top row, cell second from left) as their total for the trial

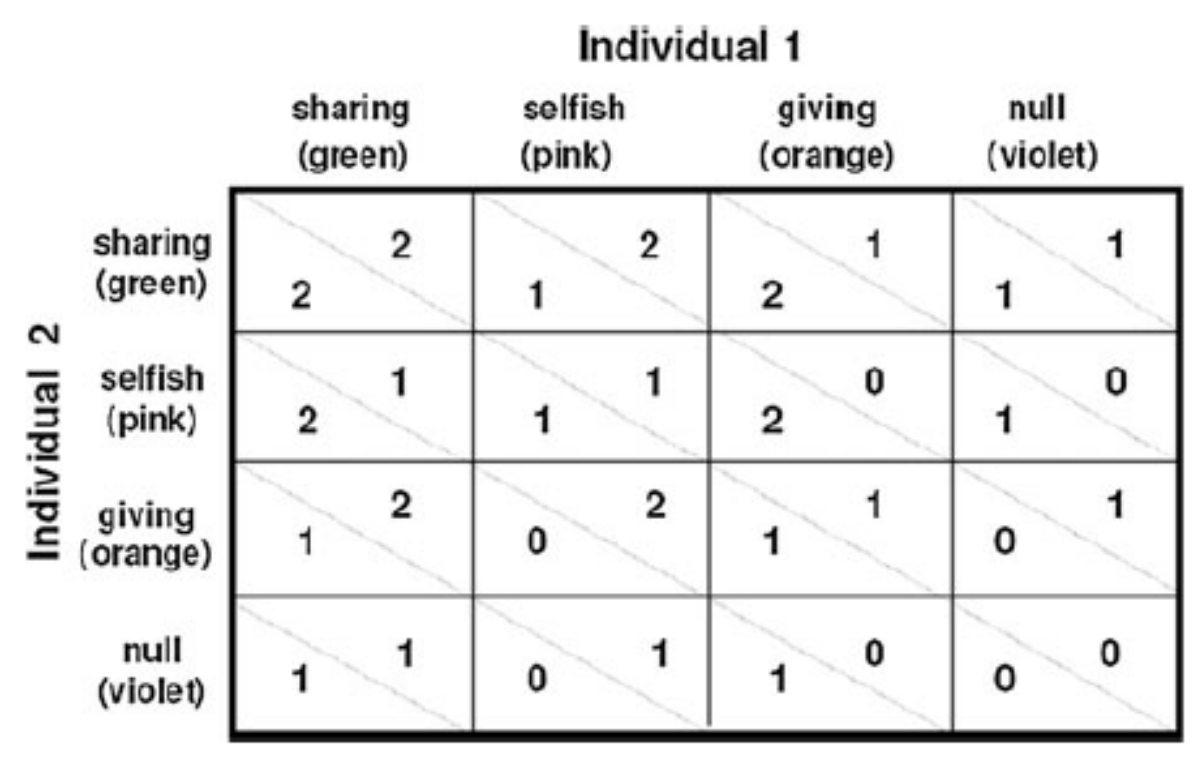

Birds engaged in 50 sessions of 20 choices-10 for each bird-having two sessions most weekdays and some weekend days for approximately 1 month. Of these 50 sessions, Griffin led in 24 and Arthur led in 26 (one session was inverted by mistake). The large number of sessions enabled us to distinguish shortterm tit-for-tat versus longer-term interactions. Experimenters did not perform more than two sessions on any given day; occasionally a single session occurred because of human scheduling.

Given the value of each cup and that individuals acted successively, a payoff matrix could be constructed, based on the birds' paired choices (see Fig. 2). If the birds did attend-or learned to attend-to each other's actions and reciprocated by choosing the green (sharing) cup, they could maximize the payoff, because each bird would receive a reward on each turn. Whether they would act in this manner was the subject of this Experiment.

\section{Demonstrations}

To assist birds in understanding the value of each choice of cup colour, rather than their having to learn entirely via trial-and-error, they received brief demonstrations prior to testing, using our standard Model/Rival technique (Pepperberg 1981, 1999; Pepperberg and Wilkes 2004). In each demonstration, two humans sequentially showed birds the consequences of choosing a particular cup; a third person distributed rewards accordingly. Birds saw 12 choices alternating among the cup colours (i.e. 3/colour). 
These demonstrations helped birds acquire an understanding of the basic concept of the task, but birds were not trained to perform in any particular manner, as all consequences were demonstrated equally.

Fig. 3 Experiment 1. Comparison of parrots' initial and final behaviour (20 trials/bird) depending on whether they were the first or second bird to choose a cup within a session

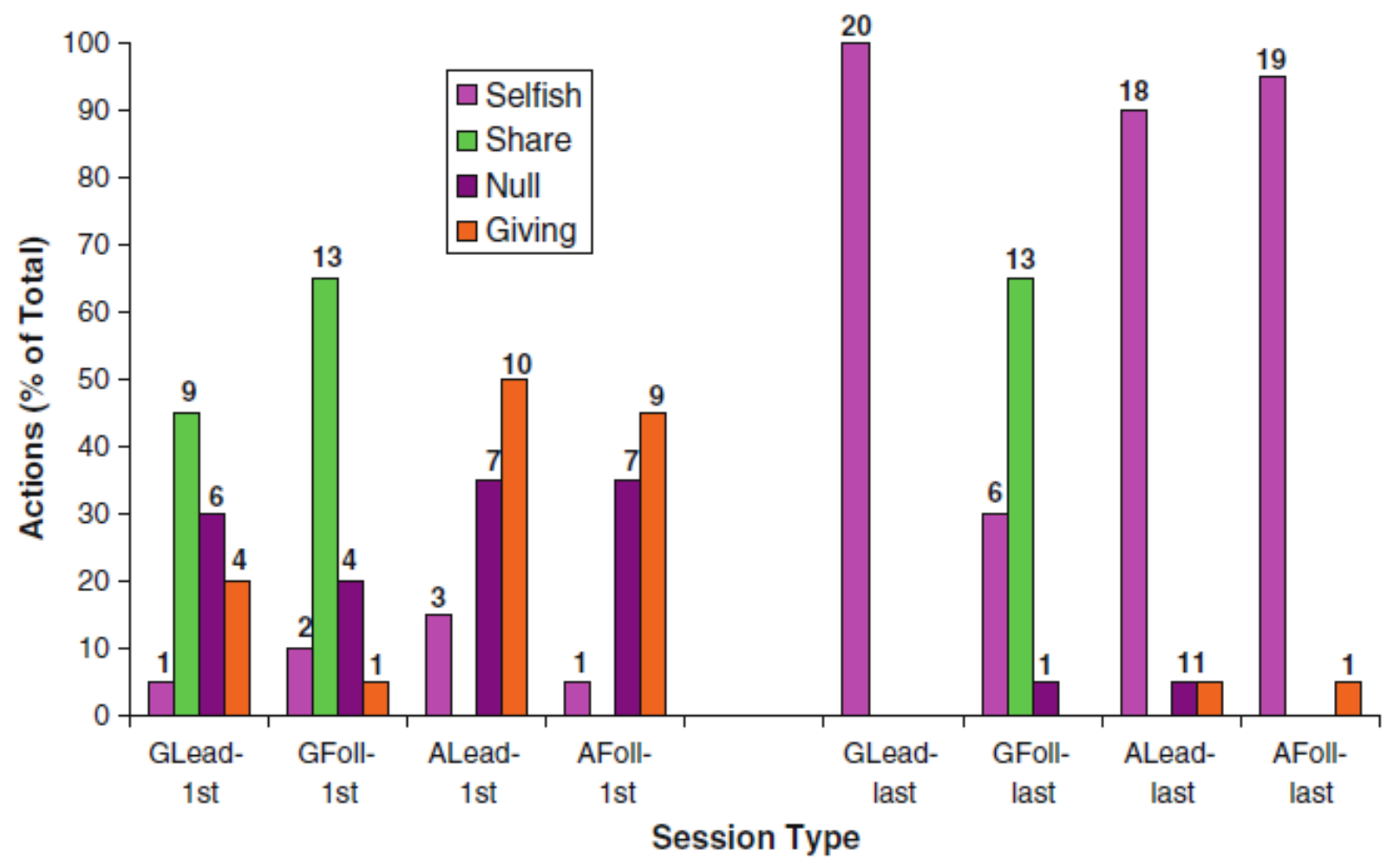

\section{Results}

\section{Cup choices}

Both birds immediately engaged in choosing various cups. To evaluate choices, we used Chi-square tests. The first, for randomness, determined whether birds simply chose without regard to consequences. Results $\left(x^{2}=10.3, P=0.016, d f=3\right)$ showed that, overall, birds were not responding at random over all 50 sessions. We also determined whether results were the same whether Griffin or Arthur led a sessionthat is, to see whether who led and who followed affected the results. Notably, here a significant difference existed $\left(X^{2}=13.7, P<0.005\right.$, df $\left.=3\right)$. Finally, Chi-square tests showed that nonrandom choice occurred for each bird in each condition (Griffin, leader: $X^{2}=64.5, P<0.01, d f=3$; Griffin, follower: $X^{2}=$ 42.2, $P<0.01, d f=3$; Arthur, leader: $\chi^{2}=45.7, P<0.01, d f=3$; Arthur, follower: $\chi^{2}=11.6, P=0.01, d f=$ 3).

To examine effects of who led/followed and evolution of choices over time, we divided sessions with respect to which bird led and which followed, and also midway (i.e. into first and last halves with respect to session number), comparing results across each half. The full data set is shown in Figure S1. Birds learned that different cup colours represented different values and adjusted their behaviour consistent with those values: They tended to stop choosing violet (no reward) and orange (rewarding the other bird) 
and tended to increase choices of pink (selfish) or retain choices of green (sharing). Chi-square tests confirmed that birds altered behaviour patterns over time. For each bird in each role, differences between first and second halves of the study were significant. For Griffin as leader: $X^{2}=31.9, P<0.01, d f=3$; as follower: $X^{2}=31.0, P<0.01, d f=3$; for Arthur as leader: $X^{2}=13.4, P<0.01, d f=3$; as follower: $\chi^{2}=15.3$, $P<0.01, d f=3$.

Examining birds' choices in their first and last 40 trials (20 per bird; Fig. 3) highlights their behaviour: they behaved somewhat differently depending on who led or followed. When leading, Griffin shifted all his choices to selfish at the end (pink; statistically significantly, $x^{2}=30.1, P<0.01, d f=3$ ). When Griffin was the follower, although he decreased his choices of giving (orange) and null (violet), and slightly increased choice of selfish (pink), he continued sharing at the same rate, and differences between these starting and ending behaviour patterns were not significant $\left(x^{2}=3.8, P=n s, d f=3\right)$. Arthur's choices in the first sessions, both as leader and follower, were significantly different from chance (respectively, $x^{2}=11.6, P$ $=0.01, d f=3 ; X^{2}=9.2, P=0.03, d f=3$ ). He started with a slight giving tendency as both leader and follower, then became statistically significantly more selfish both as leader and follower (respectively, $X^{2}=$ $21, P<0.01, d f=3 ; X^{2}=21.3, P<0.01, d f=1$ ). Given the high variability of the data, additional statistical analyses are unlikely to provide additional information. A discussion of observable trends in the raw data, however, can be found in Electronic Supplemental Material, Figure S1 Comments. To avoid performing Chi-square with zeros, in all such cases, we added 0.5 to all values in the calculation (Field 2009). Having a large number of entries of zero and more than $20 \%$ of less than 5 precluded log-linear analyses of the full data set.

We also examined relevance of cup placement on the tray; changes are marked by arrows in Figure S1. Birds' behavior patterns sometimes changed at the point of a shift; however, even more significant behavioural differences occurred between sessions in which no changes in cup order had been made. Chi-square tests showed that behaviour before and after cup order switches was not significantly different for Griffin as leader (e.g. at session $9, X^{2}=2.1, P=n s, d f=3$ ). As a follower, Griffin's behaviour altered less when cup order changed (e.g. at session $8, X^{2}=9.9, P=0.02, d f=3$ ), than when no cup switch was made (e.g. between sessions 12 and $13, X^{2}=14.4, P<0.01, d f=3$ ). Similar results were found for Arthur. Thus cup order may have had some influence right at the point of a switch, but less so than experiencing alterations in each others' actions. Figure S1, by presenting variability in data across sessions, rather than in just initial and final sessions (Fig. 3) as in most studies, suggests that birds were likely responding to each others' cup choices.

Although Arthur was placed so as to see Griffin's behaviour, he sometimes did not seem to be observing Griffin's choices. He appeared merely to be waiting his turn to choose a reward.

\section{Vocal behavior}

During sessions, Griffin emitted three main vocalizations: calls that could be interpreted as "frustration squeaks" (see below), requests of "want nut", or statements of "nut". Arthur remained silent throughout. We recorded number and type of utterances according to the cup chosen (see Fig. 4).

Vocalizations were, overall, very few (ca. 1-2/session, where each session involved 20 choices). Griffin significantly produced more calls that had previously been associated with frustration (e.g. given when students ignore his requests, or when he fails in an endeavour) when he received none than when he received half the visible reward $\left(x^{2}=21.062, P<0.001, d f=1\right)$. Looking at the percentage per choice shows he emitted the three main utterances $33 \%$ of the time when he chose orange (22 utterances, of which 16 were squeaks, during 67 choices) and $16 \%$ of the time when Arthur chose pink (27 in 185 choices, 25 squeaks) but no more than $\sim 7 \%$ of the time when he chose green (10 in 143 choices, 5 
squeaks) or $\sim 10 \%$ of the time Arthur chose green ( 9 in 91 choices, all squeaks). He rarely vocalized when he chose pink ( 3 of 214, 2 squeaks) or Arthur chose orange ( 1 of 137,1 squeak). He also said "want nut" or "nut" more often when he received nothing versus all the reward $\left(x^{2}=6.4, P=0.011, d f=\right.$ 1 ), and less often when he received half, but only $\sim 15$ such requests occurred overall in $\sim 1,000$ choices, and because half these vocalizations were "nut", they could equally have been a comment rather than a request.

Fig. 4 Experiment 1. Griffin's vocalizations graphed as percentages relative to numbers of choices each bird made

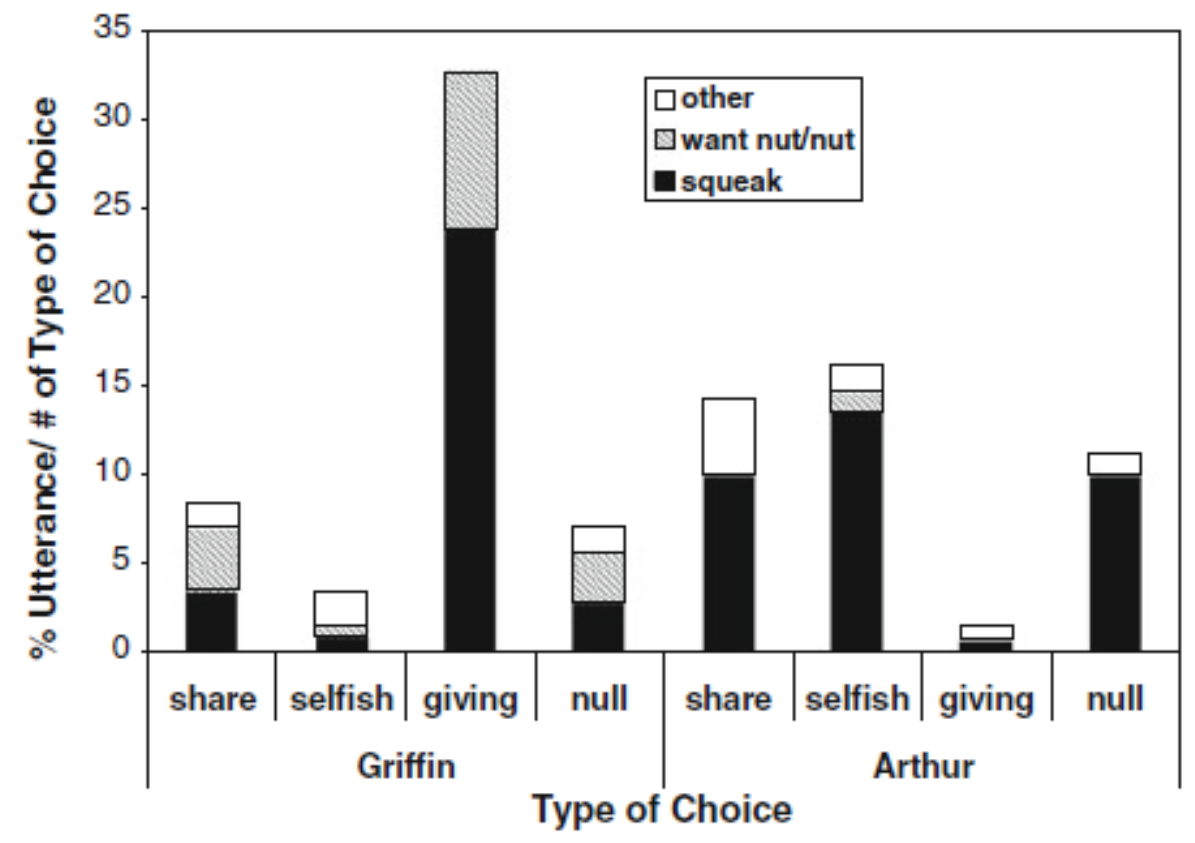

\section{Discussion}

Two main findings emerge: First, birds recognized that tokens had different values and altered their behaviour to some degree accordingly. Second, like chimpanzees in some studies (e.g. Brosnan et al. 2009; Melis et al. 2008; Silk et al. 2005), birds were not overtly eager to share or reciprocate; that is, if we combine results for their actions as both leaders and followers, they did not cooperatively act so as to maximize rewards. However, whether they shared with their partner at no cost to themselves seemed, at least for our subjects, to depend upon their dominance status and upon who led and who followed. Griffin has always been dominant to Arthur, and Figs. 3 and S1 show that when Griffin led, he became selfish, but when placed in the position of follower, he acted in a more sharing manner. Notably, both birds generally decreased their choices of giving and null cups: those choices did not result in any immediate personal reward and any overt giving was not reciprocated. Results suggest that they either did not understand the advantage of reciprocally choosing green (sharing) in order to maximize payoff, or their dominant-subordinate relationship interfered with their interactions. Possibly seeing half the reward under the green cup-which, at double the amount under the selfish (pink) and giving (orange) cups, may have seemed like a bonus-go instead to the partner might have created a negative association for the bird making the choice. Such might have been the case for Arthur. However, Griffin rarely produced calls indicating frustration in such instances and did chose green with increasing frequency as trials 
progressed when he was the follower. Had choosing green created a negative association for him, such would not have been the case.

The birds were not automatons; session-to-session variation frequently occurred (Figure S1). Possibly, birds responded not only with respect to their social/asocial tendencies per se, but also to differing daily conditions we chose not to control (e.g. how much/what types of other food they might already have had, how long since they had eaten, how much interaction they had had prior to a session, how many training/testing sessions had been held on totally different topics that day). Such conditions might stand in for variability of life in the wild that would affect their natural behaviour on this task. Conceivably, Griffin acted in a somewhat Machiavellian manner, like Massen et al.'s (2010) macaques. As leader, he responded selfishly. However, when uncharacteristically forced into a following position, he may have, in the sense of Zahavi (2004), tried to advertise his fitness via sharing, and re-establish his dominance. He was more than twice as likely to choose green as pink when a follower in the last 20 trials (Fig. 3). Massen et al. (2011), for example, argue that prosocial behaviour may signal status particularly for individuals living in fission-fusion societies, where it can be "used to signal a positive attitude in the presence of unfamiliar individuals or after reencountering known individuals..." Also, Griffin (although quite rarely) requested nuts or commented when nuts went to Arthur; one might argue such utterances could be interpreted as requests for assistance. If so, Arthur, unlike apes in some studies (e.g. Melis et al. 2011), did not respond.

Arthur, the subordinate, behaved differently. Initially, he tended towards donating treats to Griffin or a choice (null) benefitting neither (possibly conflicted between not wanting to donate but being afraid to take the treat in Griffin's presence). He thus initially acted like apes in some studies (e.g. Yamamoto et al. 2009). Because, as in a recent chimpanzee study (Horner et al. 2011), humans actually disbursed the treats, he may have learned that he could, in this unique situation in the laboratory, be selfish without fear of reprisal from Griffin; Arthur's behaviour-a shift to selfish as both leader and follower-suggests such might be the case.

Interestingly, one reason for alternating birds' positions as leader and follower had been to see whether the effect of dominance on behaviour would hold up in our laboratory if the dominant bird had to follow and the subordinate bird was given the chance to lead, that is, if we made at least some attempt to change the hierarchical nature of life in the laboratory. Data (Fig. 3, S1) demonstrate that little change occurred initially; only over the course of the experiment did birds' behaviour patterns evolve.

Clearly, our data are preliminary: We tested only two birds, and our observations about dominance/subordinance may be relevant only in our laboratory or only as part of an interactive equation. Repetition, with a flock of Greys that have socially interacted since hatching, that live in a monitored dominance hierarchy, and for whom detailed knowledge of all partnerships exists so tests can examine interconnected effects of age, sex, dominance, and social partnerships (e.g. Massen et al. 2011) would be necessary before species-wide conclusions could be formed. However, our paradigm suggests a simple, effective way to examine sharing and reciprocity in psittacids and likely other avian subjects.

\section{Experiment 2}

Because birds' responses in Experiment 1 could have been influenced by their (possible dominance) relationship with each other, we subsequently tested their behaviour in a situation that should have avoided that issue; that is, with human partners. We specifically investigated how and if the birds' behaviour (sharing or selfish) might be shaped by partners acting consistently in that manner. Also, we tested whether birds would come to understand the behaviour of a "copycat" human, who mirrored their 
actions, or whether such a partner, who changed behaviour from trial-to-trial, would prevent the avian chooser from recognizing or understanding the underlying pattern of mirroring.

\section{Protocol}

Birds were now tested individually in sessions with three different humans. One was selfish, always choosing pink; a second was giving, always choosing orange; a third mirrored whatever the bird did ("copycat"). The giving person for Arthur was selfish for Griffin and vice versa. Humans chose first for giving and selfish trials, to see how birds might respond to being the follower. Birds chose first on copycat trials, to see how human responses might affect the birds' behaviour. Different sessions were randomly interspersed, depending only on which trainer worked on a given day. For both birds, order of cup colours was changed within each session (every 5 trials) to examine their overall patterns with respect to order and to perform statistical tests. The remainder of the protocol was identical to that of Experiment 1 . Birds were already familiar with cup values; no demonstrations were needed.

In all but a few instances, birds had ten sessions of ten trials each in each condition. Given the need to maintain consistency of human partners and schedules of these partners over time, however, Griffin had only nine sessions in the giving condition and Arthur had only nine selfish sessions. We tried to give birds at least one session/day and no more than two sessions/day, but because of the number of humans involved, adherence to this schedule was difficult. Thus, on occasion (student vacation time, exam period), Arthur did not get sessions for 3 weeks or Griffin had four sessions on 1 day. Such aberrations may have affected the results (see below).

\section{Results}

Chi-square tests showed that birds did not have any spatial preference (e.g. for inner versus outer cups; Fig. 1: for Griffin, $X^{2}=2.49, P=0.11$; for Arthur, $\left.X^{2}=2.67, P=0.10\right)$. Thus their choices reflected an understanding of the value of cup colours and not preferences for spacing or position of the cups.

Both birds reacted in ways at least somewhat consistent with actions of their human partners and with their experience in Experiment 1. Both birds, in all situations, either remembered to avoid the null cup on the first session or quickly learned to avoid it; again, they also tended not to donate rewards to their human partner-that is, they avoided orange-even if the partner had chosen orange. Their responses with respect to selfishness and sharing differed somewhat for each bird and each situation. An overall summation of their choices, however, tells little about their behaviour, as it is the change in behavior relative to the different human actions that is the issue. We plot first and last sessions in each condition (10 trials each) to emphasize the birds' behavioural change over time; additional graphs provide choices for each session for each bird for each condition (Figs. S2, S3). The number of data points for 10 trials was too low for Chi-square calculations comparing first versus last sessions, and the data too erratic overall for statistical analyses; we discuss only trends that appear over time.

\section{Griffin}

Griffin interacted in ways somewhat consistent with that of his human partners (Figs. 5, S2). Some trends are apparent from the early and final sessions (Fig. 5) and the overall data (Fig. S2). When paired with a giving human (who always chose orange), Griffin's behaviour shifted in a generally straightforward way, towards sharing. He was clearly not mimicking the human or responding in a form of stimulus enhancement, because he shifted towards the sharing (green) cup, not the orange. He also decreased his selfish (pink), giving (orange), and null (violet) choices. Similarly, when paired with an always selfish human, he shifted towards selfish behaviour and away from giving, null, and sharing choices. His increase in selfishness over time and decrease in giving are apparent, particularly in the last few 
sessions. Griffin's behaviour with the copycat human demonstrates few apparent trends and would seem not to show any understanding that the human was indeed following his behaviour and that a clear change towards sharing would increase the total number of treats he might receive. However, he appears to increase sharing over time, whereas selfishness remains relatively steady and choice of the orange cup decreases.

\section{Arthur}

Arthur did not behave as consistently towards humans as did Griffin (Figs. 6, S3). For reasons described below, Fig. 6 uses session 8, not session 10, as 'last' for interactions with the giving human. Figure 6 shows that Arthur tended towards sharing with the giving human and towards selfishness with the selfish human, and that he, like Griffin, seemed confused by the copycat situation. With the "copycat", interestingly, he often stopped giving rewards, often 'opting out' by choosing the null cup; his giving (choice of orange) trended downward.

Inspection of individual sessions (Fig. S3) shows at least one interesting trend. Separation of the last two sessions, held after a three-week break-over twice as long as any other break in the entire experimentappears important for analysis: With the giving human, he was tending towards an increase in sharing and a decrease in selfishness before the break, with a clear reversal afterwards.

Fig. 5 Experiment 2. Comparisons of Griffin's initial and final sessions for the three different human interactions, based on percentages of his total responses

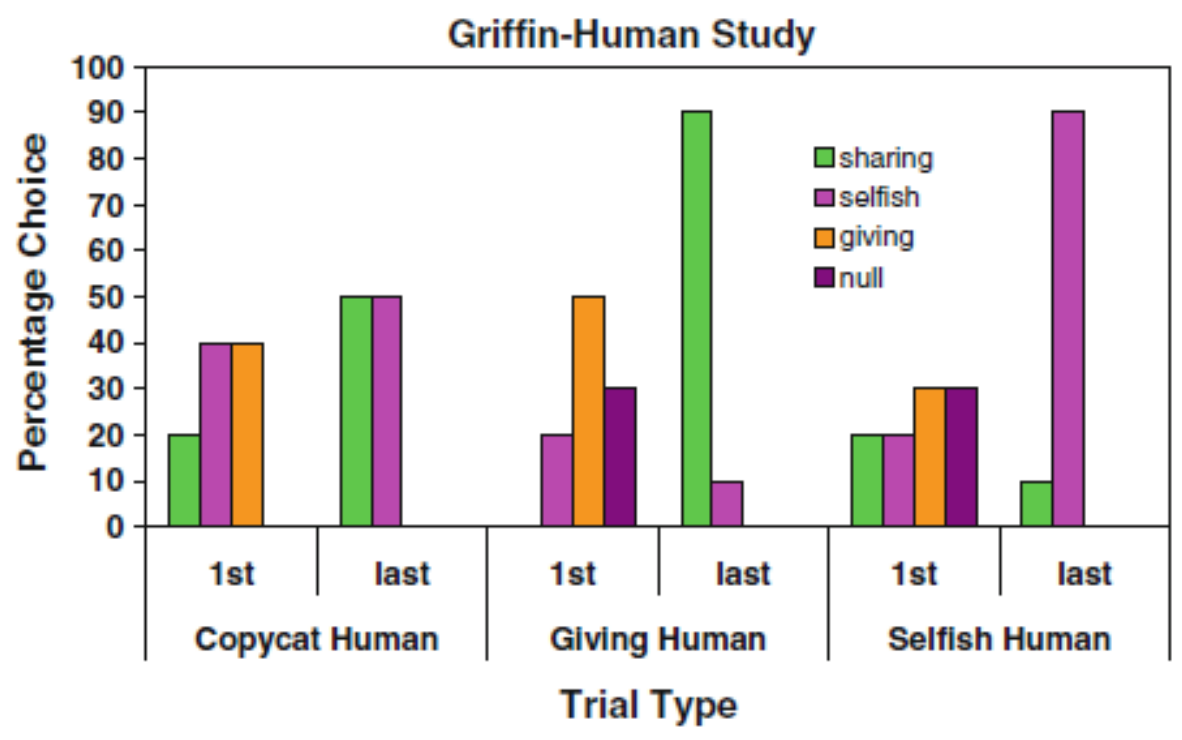

\section{Discussion}

When intraspecies interactions were not relevant and humans acted consistently, at least one Grey parrot appeared to develop some understanding of sharing and reciprocity. Griffin's actions with a consistently giving trainer suggested he might have inferred that choosing green (sharing) would ensure he received a maximum number of rewards and that he could reward his giving partner at no real cost to himself. He could have consistently been selfish and garnered the same reward level, but did not. He was definitely not copying the human's behaviour overall, because the human consistently gave him the immediate reward-chose orange. Arthur, in contrast, did not seem willing to give that partner much reward, even at 
no cost to himself, although he did trend towards sharing with the giving trainer before the three week break. Possibly, Arthur, who, unlike Griffin, often reacts to an absence by a student with whom he has previously had positive interactions (e.g. allows to scratch his head) by seriously biting or ignoring this human upon his/her return, might have used a selfish choice to indicate his displeasure at being 'abandoned' for the 3-week hiatus.

Fig. 6 Experiment 2. Comparisons of Arthur's initial and not-quite final sessions (because of the 3-week testing break) for the three different human interactions, based on percentages of his total responses

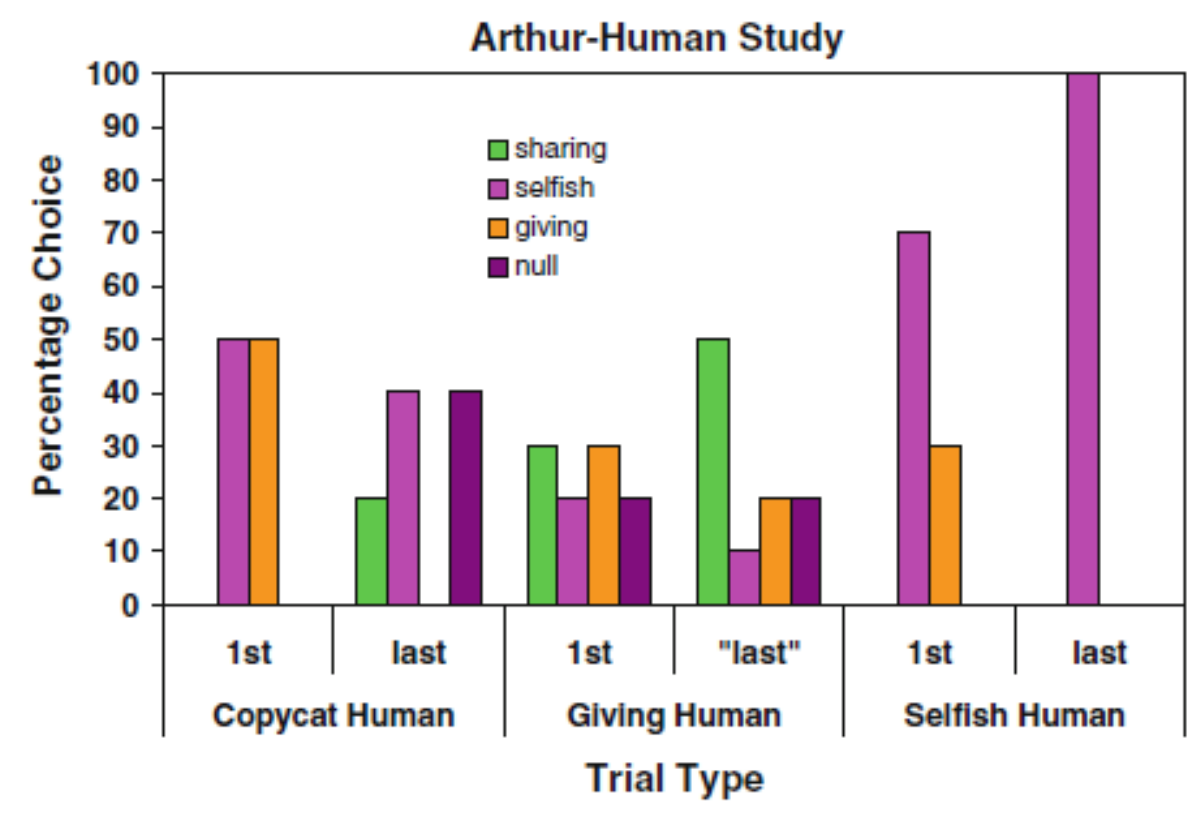

Birds also differed with respect to the selfish human partner. Griffin became considerably more selfish, suggesting that he again altered his responses based on those of his partner. Arthur was already selfish in the first session with the selfish partner, possibly immediately reacting to the observed selfishness, but his subsequent behaviour was mostly random until the final session. Though no long breaks occurred in Arthur's interactions with the selfish trainer, unlike the break with the generous one, conceivably the selfish behaviour transferred between those final sessions, as they were held during the same time period.

The copycat situation, where the human partner acted neither consistently generously nor selfishly, seemed to confuse the birds. Griffin did not respond in a clearly consistent manner. Had he consistently chosen green, we would have had evidence that he inferred the underlying principle: by sharing at no cost to himself, his partner would reciprocate and he could maximize rewards. He did, however, trend in the appropriate direction; thus, possibly, he had begun to test out an inference about the reciprocity of the situation. Had sessions extended for a longer period (as in Experiment 1), maybe he would have responded appropriately. Arthur at first trended towards sharing, but, in contrast, halfway through changed his behaviour; his tendency towards an increase in the null response (violet) might suggest a lack of willingness to continue to participate in the interactions.

Again, as in Experiment 1, we summarize changes over time in Figs. 5 and 6, and present full data sets in Figures S2 and S3. A clearer case for sharing and reciprocity could be made with the summary data; 
however, Figures S2 and S3 show that despite some trends, session-to-session variability existed, again probably as a result of the other laboratory conditions noted above.

Though Griffin and Arthur had both been previously extensively trained by humans via the Model/Rival method (Pepperberg 1981), and thus expect humans to demonstrate behaviour patterns they are to learn, such training did not likely affect their overall behaviour here. Training background might have affected their initial choices_for example, with the giving human who always picked orange-but clearly had no effect by the final session. Importantly, only the copycat human ever picked green (sharing), but Griffin clearly switched to green with the giving human, suggesting that he, at least, began to understand the issues involved.

Note, too, that although several weeks elapsed between Experiments 1 and 2, birds likely remembered the values of the cups, as can be seen, for example, by their low choice of null (violet) on several initial sessions. Thus any learning curves in Experiment 2 were likely to be solely related to their reactions to the different social systems.

\section{General discussion}

Overall, we found three interesting results. First, both birds were sensitive to token values (i.e. cup colour). Second, the relationship between the birds may have affected their interactions, but in somewhat unexpected ways. Third, when working with humans, Griffin's responses suggested some possible understanding of reciprocity and sharing, whereas Arthur's behaviour was more variable.

Both parrots were sensitive to the value of their choices and, to some extent, altered their behaviour accordingly. When working together, both birds learned to avoid cups (violet, orange) representing, and resulting in, lack of personal reward. Arthur, in particular, learned about aspects of the task specifically related to reward disbursement: He-our subordinate-initially either chose orange (giving) or null as both leader and follower (possibly waffling between acceding to our dominant and avoiding any nut disbursement), but became more selfish over time in both instances. Possibly he began to realize that, as humans disbursed rewards, Griffin could not punish his selfishness.

Parrots were also somewhat sensitive to reward distributions (i.e. consequences of cup colour) under various conditions. In Experiment 1, possibly the relationship between the two birds and whether they acted as follower or leader affected the extent to which they demonstrated sharing and reciprocity. In Experiment 2, Griffin appeared sensitive to the actions of his human partners, whereas Arthur demonstrated less consistency, although some responses may have been a consequence of session scheduling and the extended absence of one human partner.

We have studied only one pair of birds and clearly cannot draw widespread conclusions about dominance effects, but our data on dominance/subordinance can be used for comparisons with subsequent studies. In Experiment 1, our subordinate Arthur, like Massen et al.'s (2010) long-tailed macaques, seemed to learn he could be selfish without immediate consequences-that is, without fear of physical reprisal, whether he led or followed. Specifically, he began Experiment 1, both as leader and follower, by donating roughly half the rewards to Griffin, but ended by being almost exclusively selfish. Such behaviour suggests that Arthur learned he could gain an unusual advantage over our dominant bird. Even when working with humans (Experiment 2), Arthur showed little regard for the actions of the copycat partner. His response to the giving partner trended towards sharing before a three-week break in sessions, but became selfish afterwards. Although the point of using humans here was to avoid dominance/subordiance issues, conceivably Arthur transferred his subordinate status with respect to Griffin to interactions with his human partners, given that humans in general are his source of food, drink, 
and social interaction in our laboratory. Interestingly, as noted above, he responded to the long absence of the giving partner by changing his behaviour towards her.

In Experiment 1, Griffin, as the dominant leader, possibly began by acting as though he could "afford" (in the sense of Zahavi 2004) to be generous at no cost to himself, but became selfish when his actions were not reciprocated. In contrast, however, when forced into the unusual position of follower, he did not alter the level of his sharing. As suggested by Massen et al. (2010), prosociality (or in our case, sharing) in a dominant might be a strategy to maintain—or here-reaffirm dominance (note de Waal 1989; Moore 1984; Zahavi 2004). Griffin's behaviour in Experiment 2 was consistent with the possibility that he did not see himself as dominant with respect to the humans in the laboratory: He became more willing to share with the giving human, selfish with the selfish human, and might have been tending towards sharing and reciprocity with the copycat human. Despite changes over time that suggest that Griffin, at least, began to behaviourally adjust to his partners' actions, we cannot claim that he was intentionally acting in a "tit-fortat" manner.

During copycat sessions, neither bird seemed to realize that the human was indeed mirroring his behaviour, although Griffin may have understood the situation towards the end of the experiment. Conceivably, birds simply did not connect their behaviour with that of the human and instead may have interpreted the human as behaving erratically, in contrast to the other humans who demonstrated a specific agenda during the same time period. We suggest that copycat trials subsequently be performed as a separate experiment, without being contrasted with trials in which humans acted consistently, to determine whether results might have differed. Possibly, the birds needed consistency on the part of their partners to understand the interactions-or maybe short-term tit-for-tat is not as important as developing long-term interactions for long-lived individuals.

Overall, birds were sensitive to context. Our mass trial procedure, the long break between sessions for Arthur in Experiment 2 (described above), and the occasional large number of sessions on 1 day, may all have affected both the parrots' willingness to work and their responses. For example, in a third session in 1 day, Arthur's null choice (violet) five of 10 times (Fig. S3) might have been his way of expressing lack of interest in continuing to work rather than a response to the specific actions of the human. Massing of trials (i.e. 10/bird/session) was necessary, given that birds needed the opportunity to decode any given situation, but possibly caused boredom and satiety. Switching treats may have alleviated, but likely did not eliminate, these issues.

Another explanation for our birds' behavioural differences is that Arthur may not be as cognitively advanced as Griffin. However, other studies, particularly on string-pulling (e.g. Pepperberg 2004) and a current trap-tube study, show that Arthur is adept (possibly more so than Griffin) at solving various 'insight' tasks. Conceivably, however, Arthur's insight into physical situations might not transfer to social interactions.

Comparing Grey parrot understanding of reciprocity and sharing to that of other nonhuman species, particularly with respect to prosociality, is difficult. As noted in the introduction, nonhuman primate data also seem extremely dependent upon experimental context, and our design was only somewhat similar to that of Horner et al. (2011). In particular, our study was conducted simultaneously with several other ongoing studies, as is the tradition in our laboratory and as a means of more likely replicating conditions outside of a laboratory. Again, although we have tested only one pair, we suggest that our birds' behavior patterns somewhat resemble those of monkeys having dominance hierarchies (e.g. macaques, Massen et al. 2010), and that subsequent studies with more birds must be conducted to test our supposition. Of interest might be comparative studies with cooperatively breeding corvids, such as Florida scrub jays (Aphelocoma coerulescens). In cooperatively breeding green wood hoopoes (Phoeniculus purpureus), 
the dominant pair increases allopreening of helpers (who provide much of the territorial defence) when the group enter zones of potential conflict with neighbouring groups and decreases allopreening when the focal group leaves such zones (Radford 2011). Such behavioural change comes at a cost-for example, less time for feeding - and suggests that dominant birds might be trading preening for support, a form of reciprocity.

In sum, some level of reciprocity and sharing appears not to be limited to the primate line. Likely the same evolutionary pressures that were exerted to develop advanced cognitive and communicative abilities in both primates and certain avian species (e.g. Emery 2004; Pepperberg 1999) also were engaged in the development of reciprocity and sharing. The expression of such behaviour is, however, fragile in birds as well as primates, and very heavily dependent upon the various contexts in which it is examined (note Horner et al. 2011; Warneken et al. 2011).

\section{Acknowledgments}

Péron was financially supported by the grant of Aires Culturelles 09 of the University of Paris Ouest Nanterre La Défense, the Dufrenoy foundation and the ED139. This experiment was designed within the framework of the 'Integrating Cooperation Research Across Europe' project and the PReCog (Parrot Research group on Cognition) project. Pepperberg and Sapowicz were supported in part by donors to The Alex Foundation (particularly the Marc Haas Foundation, the Pearl Family Foundation, Anita Keefe, Janice Boyd, Alex and Michael Shuman, the Anders Sterner family, Nancy Chambers, Greg LaMorte, Kathryn and Walter McAdams, Joseph Golden, Megumi Oka and the Makioka Foundation), and partially from the National Science Foundation (grants BCS-0920878 and BCS-1026256) to Ken Nakayama; any opinions, findings, and conclusions, or recommendations expressed in this publication are those of the author and do not necessarily reflect the views of the National Science Foundation. We thank Bill Heess, Samuel Moulton, and Maryam Vaziri Pashkam for advice and assistance with statistical analyses, Anna Schwartz for assistance in Experiment 2, and Felix Warneken for comments and discussion. The study procedures comply with the current laws of the USA, where they were performed.

\section{References}

Bell AV, Richerson PJ, McElreath R (2009) Culture rather than genes provides greater scope for the evolution of large-scale human prosociality. PNAS 106:17671-17674

Boysen ST, Berntson GG, Hannan MB, Cacioppo JT (1996) Quantity-based interference and symbolic representations in chimpanzees (Pan troglodytes). J Exp Psychol Anim Behav Proc 22:76-86

Brosnan SF, Beran MJ (2009) Trading behavior between conspecifics in chimpanzees, Pan troglodytes. J Comp Psychol 123:181-194

Brosnan SF, Freeman C, de Waal FBM (2006) Partner's behavior, not reward distribution, determines success in an unequal cooperative task in capuchin monkeys. Am J Primatol 68:713-724

Brosnan SF, Silk JB, Henrich J, Mareno MC, Lambeth SP, Schapiro SJ (2009) Chimpanzees (Pan troglodytes) do not develop contingent reciprocity in an experimental task. Anim Cogn 12:587597

Bugnyar T (2007) An integrative approach to the study of ToM-like abilities in ravens. Jpn J Anim Psychol 57:15-27

Bullinger AF, Melis AP, Tomasello M (2011) Chimpanzees, Pan troglodytes, prefer individual over collaborative strategies toward goals. Anim Behav 82:1135-1141 
Burkart JM, Fehr E, Efferson C, van Schaik CP (2007) Other-regarding preferences in a non-human primate: common marmosets provision food altruistically. PNAS 104:19762-19766

Call J, Tomasello M (1998) Distinguishing intentional from accidental actions in orangutans (Pongo pygmaeus), chimpanzees (Pan troglodytes), and human children (Homo sapiens). J Comp Psychol 112:192-206

Call J, Hare B, Carpenter M, Tomasello M (2004) 'Unwilling' versus 'unable’: chimpanzees' understanding of human intentional action. Dev Sci 7:488-498

Clayton NS, Emery NJ (2005) Corvid cognition. Curr Biol 15:R80-R81

Cronin KA, Snowdon CT (2008) The effects of unequal reward distributions on cooperative problem solving by cottontop tamarins (Saguinus oedipus). Anim Behav 75:245-257

Cronin KA, Schroeder KKE, Rothwell ES, Silk JB, Snowdon CT (2009) Cooperatively breeding cottontop tamarins (Saguinus oedipus) do not donate rewards to their long-term mates. J Comp Psychol 123:231-241

Cronin KA, Schroeder KKE, Snowdon CT (2010) Prosocial behavior emerges independent of reciprocity in cottontop tamarins. Proc R Soc B Biol Sci 277:3845-3851. doi:10.1098/rspb.2010.0879

Dawkins MS (2010) Do asymmetries destabilize the Prisoner's Dilemma and make reciprocal altruism unlikely? Anim Behav 80:339-341

de Waal FBM (1989) Food sharing and reciprocal obligations among chimpanzees. J Hum Evol 18:433459

de Waal FBM (1997) The chimpanzee's service economy: food for grooming. Evol Hum Behav 18:375386

de Waal FBM, Leimgruber K, Greenberg AR (2008) Giving is self-rewarding for monkeys. PNAS 105:13685-13689

DiLascio F, Neffleler F, Bshary R, Bugnyar T (2012) Ravens (Corvus corax) are indifferent to the gains of conspecific recipients or human partners in experimental tasks. Anim Cogn. doi:10.1007/s10071012-0548-0

Dufour V, Pelé M, Neumann M, Thierry B, Call J (2009) Calculated reciprocity after all: computation behind token transfers in orangutans. Biol Lett 5:172-175

Emery NJ (2004) Are corvids 'feathered apes'? Cognitive evolution in crows, jays, rooks and jackdaws. In: Watanabe S (ed) Comparative analysis of minds. Keio University Press, Tokyo, pp 181-213

Emery NJ, Seed AM, von Bayern AM, Clayton NS (2007) Cognitive adaptations of social bonding in birds. Phil Trans R Soc B Biol Sci 362:489-505

Field A (2009) Discovering statistics using SPSS, 3rd edn. Sage Publications, Los Angeles

Fraser ON, Bugnyar T (2010a) Do ravens show consolation? Responses to distressed others. PLoS ONE 5:e10605. doi:10.1371/journal.pone.0010605

Fraser ON, Bugnyar T (2010b) The quality of social relationships in ravens. Anim Behav 79:927-933

Fraser ON, Bugnyar T (2011) Ravens reconcile with valuable partners after aggressive conflicts. PLoS ONE 6:e18118. doi:10.1371/journal.pone.0018118

Giret N, Miklósi A, Kreutzer M (2009) Use of experimenter-given cues by African gray parrots (Psittacus erithacus). Anim Cogn 12:1-10

Greenberg JR, Hamann K, Warneken F, Tomasello M (2010) Chimpanzee helping in collaborative and noncollaborative contexts. Anim Behav 80:873-880

Hamilton WD (1964) The genetical evolution of social behaviour. I \& II. J Theor Biol 7:1-52. doi:10.1016/0022-5193-64-90038-4

Hamilton WD (1975) Innate social aptitudes of man: an approach from evolutionary genetics. In: Fox R (ed) Biosocial anthropology. Wiley, New York, pp 133-155

Hattori Y, Kuroshima H, Fujita K (2005) Cooperative problem solving by tufted capuchin monkeys (Cebus apella): spontaneous division of labor, communication, and reciprocal altruism. J Comp Psychol 119:335-342 
Henderson AME, Woodward AL (2011) "Let's work together": what do infants understand about collaborative goals? Cognition 121:12-21

Horner V, Carter JD, Suchak M, de Waal FBM (2011) Spontaneous prosocial choice by chimpanzees. PNAS 108:13847-13851

Hrdy S (2009) Mothers and others: the evolutionary origins of mutual understanding. Harvard University Press, Cambridge

Humphrey NK (1976) The social function of intellect. In: Bateson PPG, Hinde RA (eds) Growing points in ethology. Cambridge University Press, Cambridge, pp 303-317

Jensen K, Hare B, Call J, Tomasello M (2006) What's in it for me? Self-regard precludes altruism and spite in chimpanzees. Proc R Soc B Biol Sci 273:1013-1021

Jolly A (1966) Lemur social behaviour and primate intelligence. Science 153:501-506

Jones P, Tye A (2006) The birds of São Tomé \& Príncipe, with Annobón, islands of the Gulf of Guinea: an annotated checklist. British Ornithologists' Union, Oxford

Kärtner J, Keller H, Chaudhary N (2010) Cognitive and social influences on early prosocial behaviour in two sociocultural contexts. Dev Psychol 46:905-914

Lakshminarayanan VR, Santos LR (2008) Capuchin monkeys are sensitive to others' welfare. Curr Biol 18:999-1000

Massen JJM, van den Berg LM, Spruijt BM, Sterck EHM (2010)Generous leaders and selfish underdogs: pro-sociality in despotic macaques. PLoS ONE 5(3):e9734. doi:10.1371/journal.pone.0009734

Massen JJM, Luyten IJAF, Spruijt BM, Sterck EHM (2011) Benefiting friends or dominants: prosocial choices mainly depend on rank position in long-tailed macaques (Macaca fascicularis). Primates $52: 237-247$

May DL (2004) The vocal repertoire of Grey parrots (Psittacus erithacus) living in the Congo Basin. PhD Dissertation, University of Arizona, Tucson

Melis AP, Hare B, Tomasello M (2008) Do chimpanzees reciprocate received favours? Anim Behav 76:951-962

Melis AP, Hare B, Tomasello M (2009) Chimpanzees coordinate in a negotiation game. Evol Hum Behav 30:381-392

Melis AP, Warneken F, Jensen K, Schneider A-C, Call J, Tomasello M (2011) Chimpanzees help conspecifics obtain food and nonfood items. Proc R Soc B Biol Sci 278:1405-1413

Moore J (1984) The evolution of reciprocal sharing. Ethol Sociobiol 5:5-14

Pelé M, Dufour V, Thierry B, Call J (2009) Token transfers among great apes (Gorilla gorilla, Pongo pygmaeus, Pan paniscus, and Pan troglodytes): species differences, gestural requests, and reciprocal exchange. J Comp Psychol 123:375-384

Pelé M, Thierry B, Call J, Dufour V (2010) Monkeys fail to reciprocate in an exchange task. Anim Cogn 13:745-751. doi:10.1007/s10071-010-0325x

Pepperberg IM (1981) Functional vocalizations by an African Grey parrot. Z Tierpsychol 55:139-160

Pepperberg IM (1990) Cognition in an African grey parrot (Psittacus erithacus): further evidence for comprehension of categories and labels. J Comp Psychol 104:42-51

Pepperberg IM (1999) The Alex studies: cognitive and communicative abilities of Grey parrots. Harvard University Press, Cambridge

Pepperberg IM (2004) "Insightful" string-pulling in Grey parrots (Psittacus erithacus) is affected by vocal competence. Anim Cogn 7:263-266

Pepperberg IM (2006a) Grey Parrot (Psittacus erithacus) numerical abilities: addition and further experiments on a zero-like concept. J Comp Psychol 120:1-11

Pepperberg IM (2006b) Ordinality and inferential abilities of a Grey Parrot (Psittacus erithacus). J Comp Psychol 120:205-216

Pepperberg IM (2010) Vocal learning in Grey parrots: a brief review of perception, production, and crossspecies comparisons. Brain Lang 115:81-91 
Pepperberg IM, Carey S (2012) Grey parrot number acquisition: the inference of cardinal value from ordinal position on the numerical list. Cognition. doi:10.1016/j.cognition.2012.07.003

Pepperberg IM, Gordon JD (2005) Numerical comprehension by a Grey Parrot (Psittacus erithacus), including a zero-like concept. J Comp Psychol 119:197-209

Pepperberg IM, Shive HA (2001) Simultaneous development of vocal and physical object combinations by a Grey parrot (Psittacus erithacus): bottle caps, lids, and labels. J Comp Psychol 115:376-384

Pepperberg IM, Wilcox SE (2000) Evidence for a form of mutual exclusivity during label acquisition by Grey parrots (Psittacus erithacus)? J Comp Psychol 114:219-231

Pepperberg IM, Wilkes SR (2004) Lack of referential vocal learning from LCD video by Grey parrots (Psittacus erithacus). Interact Stud 5:75-97

Pepperberg IM, Willner MR, Gravitz LB (1997) Development of Piagetian object permanence in a Grey parrot (Psittacus erithacus). J Comp Psychol 111:63-75

Pepperberg IM, Naughton JR, Banta PA (1998) Allospecific vocal learning by Grey parrots (Psittacus erithacus): a failure of videotaped instruction under certain conditions. Behav Process 42:139158

Pepperberg IM, Gardiner LI, Luttrell LJ (1999) Limited contextual vocal learning in the Grey parrot (Psittacus erithacus): the effect of co-viewers on videotaped instruction. J Comp Psychol 113:158-172

Pepperberg IM, Sandefer RM, Noel D, Ellsworth CP (2000) Vocal learning in the Grey parrot (Psittacus erithacus): effect of species identity and number of trainers. J Comp Psychol 114:371-380

Péron F, Rat-Fischer L, Nagle L, Bovet D (2010) 'Unwilling' versus 'Unable': grey parrots' understanding of human intentional action? Interact Stud 11:428-441

Péron F, Chardard C, Nagle L, Bovet D (2011a) Do African grey parrots (Psittacus erithacus) know what a human experimenter does and does not see? Behav Process 87:237-240

Péron F, Rat-Fischer L, Lalot M, Nagle L, Bovet D (2011b) Cooperative problem solving in African grey parrots (Psittacus erithacus). Anim Cogn. doi:10.1007/s10071-011-0389-2

Phillips W, Barnes JL, Mahajan N, Yamaguchi M, Santos LR (2009) Unwilling versus unable: capuchin monkeys (Cebus apella) understanding of human intentional action. Dev Sci 12:938-945

Radford AN (2011) Preparing for battle? Potential intergroup conflict promotes current intragroup affiliation. Biol Lett 7:26-29

Rustagi D, Engel S, Kosfeld M (2010) Conditional cooperation and costly monitoring explain success in forest commons management. Science 330:961-965

Scheid C, Schmidt J, Noë R (2008) Distinct patterns of food offering and co-feeding in rooks. Anim Behav 76:1701-1707

Schwab C, Swoboda R,Kotrschal K, Bugnyar T (2012) Recipients affect prosocial and altruistic choices in jackdaws, Corvus monedula. PLOS One 7(4):e34922. doi:10.1371/journal.pone.0034922

Seed AM, Clayton NS, Emery NJ (2008) Cooperative problem solving in rooks (Corvus frugilegus). Proc R Soc Lond B Biol Sci 275:1421-1429

Silk JB, Brosnan SF, Vonk J, Henrich J, Povinelli DJ, Richardson AS, Lambeth SP, Mascaro J, Schapiro SJ (2005) Chimpanzees are indifferent to the welfare of unrelated group members. Nature 437:1357-1359

Simpson JA, Beckes L (2009) Evolutionary perspectives on prosocial behavior. In: Mukulincer M, Shaver PR (eds) Prosocial motives, emotions, and behavior. American Psychological Association, Washington, pp 35-53

Stevens JR (2010) Donor payoffs and other-regarding preferences in cotton-top tamarins (Saguinus oedipus). Anim Cogn 13:663-670

Takimoto A, Kuroshima H, Fujita K (2010) Capuchin monkeys (Cebus apella) are sensitive to others' reward: an experimental analysis of food-choice for conspecifics. Anim Cogn 13:249-261 
von Bayern AMP, de Kort SR, Clayton NS, Emery NJ (2007) The role of food- and object-sharing in the development of social bonds in juvenile jackdaws (Corvus monedula). Behaviour 144:711-733

Vonk J, Brosnan SF, Silk JB, Henrich J, Richardson AS, Lambeth SP, Schapiro SJ, Povinelli DJ (2008) Chimpanzees do not take advantage of very low cost opportunities to deliver food to unrelated group members. Anim Behav 75:1757-1770

Warneken F, Hare B, Melis AP, Hanus D, Tomasello M (2007) Spontaneous altruism by chimpanzees and young children. PLoS Biol 5:e184. doi:10:1371/journal.pbio.0050184

Warneken F, Lohse K, Melis AP, Tomasello M (2011) Young children share the spoils after collaboration. Psychol Sci 22:267-273

Yamamoto S, Tanaka M (2009) Do chimpanzees (Pan troglodytes) spontaneously take turns in a reciprocal cooperation task? J Comp Psychol 123:242-249

Yamamoto S, Humle T, Tanaka M (2009) Chimpanzees help each other upon request. PLoS ONE 4:e7416. doi:10.1371/journal.pone.0007416

Zahavi A (2004) The details of food-sharing interactions-their cost in social prestige. Behav Brain Sci 27:570-571 